\title{
EDITORIAL \\ Penetrating spinal trauma: snapshot of the American epidemic
}

\author{
R. John Hurlbert, MD, PhD, FRCSC \\ Department of Surgery, University of Arizona, Tucson, Arizona
}

$\mathrm{D}$ R. Morrow and colleagues' article on penetrating spine trauma is a sobering reality check indeed. ${ }^{3}$ For every 100 patients with a spinal fracture at their institution, 10 are from a gunshot wound. Almost half of those have an associated neurological deficit, most likely to be a permanent motor- and sensory-complete spinal cord injury. Patients with penetrating trauma have more serious associated injuries, consume more acuteand long-term care, and are less likely to be discharged home than those with blunt spine trauma.

What is interesting to me is the lower incidence of alcohol inebriation, attesting to the fact that these are planned assaults and not accidents. That injury levels are distributed evenly throughout cervical, thoracic, and lumbosacral regions indicates the spine to be collateral damage rather than the focus of targeted violence. Underscoring the authors' premise that management of this patient population does not lend itself to our usual spine trauma guidelines is the observation that, while $40 \%$ of their patients sustained a spinal cord injury, only 5\% of the entire cohort underwent surgery, which is diametrically opposite from our typical blunt trauma experience. The unusual injury patterns and unique challenges these injuries pose to our biomechanical intuitions are exquisitely demonstrated in the case illustration provided. It should not be surprising to the reader that these authors confirm a more dismal prognosis from penetrating spinal cord injury than from blunt trauma; even mean arterial pressure therapy cannot be expected to reduce secondary injury in the setting of axonal transection.

From a bird's-eye view, the demographics of Morrow and colleagues' population are almost as sobering as the injury patterns themselves: young males in their late $20 \mathrm{~s}$ and early 30s; socio-economically disadvantaged; 4 of every 5 victims being African American; injuries sustained from intent-to-harm violence in $93 \%$ of cases. Alarmingly similar demographics play out in firearm-associated deaths. ${ }^{2,5}$ Researchers from the University of Washington have gone on to confirm that survivors are at heightened risk for subsequent violent persecution and crime perpetration. ${ }^{6}$ These haunting statistics seem to argue for segments of our society ignored and left to fend for themselves.

We have all heard it before, that the mortality rate from firearms in the United States compares very poorly to those of other countries we consider "civilized." Recently, the United States became second in the world for total number of domestic firearm deaths, boasting over 37,000 people shot and killed in 2016. ${ }^{4}$ Of our British, European, Australian, and Canadian cousins, only France shares the top 20 list with the United States, coming in with a paltry 2300 dead by comparison. When adjusted per capita, the United States drops to 20 behind third-world countries in South America, the Caribbean, the Middle East, and Mexico, but we generally remain an order of magnitude ahead of the first-world countries in gun-related deaths per 100,000 population. $^{4}$

In 2018, the American College of Physicians updated their position statement on reducing firearms injuries and deaths in the United States. ${ }^{1}$ The recommendations were originally developed in collaboration with the American College of Surgeons, the American Academy of Family Physicians, the American College of Emergency Physicians, and the American Bar Association. The document identifies 10 tangible steps as part of a process, identified through extensive literature review and stakeholder input. Although far from perfect and arguably written from a biased perspective, the recommendations themselves are compelling in their face validity. The primary plea for a nonpartisan public health approach to firearms-related violence through consensus building by coalitions of stakeholders is only befitting for a society that champions democracy on a global scale.

Currently, from the front lines of neurotrauma in south- 
ern Arizona, it is clear to me that much more than a position statement is needed to combat the American epidemic of penetrating trauma. However, for us as physicians, it is a big start. We have a voice. More than ever, we are learning to exercise it. And the public is interested in what we have to say. In a country where it is easier to get a gun than it is a driver's license, there is a lot of room to promote change.

As Morrow and colleagues appropriately point out in their article, there is certainly a need to better define injury patterns and care pathways for penetrating spine trauma. But there is an equally important need for our advocacy in understanding and helping these people in high-risk demographically insulated communities, people who feel they have nowhere left to turn. Morrow and colleagues are to be congratulated for keeping this problem front and center, and for sharing their experience in such an objective manner. ${ }^{3}$

https://thejns.org/doi/abs/10.3171/2019.1.FOCUS1913

\section{References}

1. Butkus R, Doherty R, Bornstein SS: Reducing firearm injuries and deaths in the United States: a position paper from the American College of Physicians. Ann Intern Med 169:704-707, 2018
2. Kalesan B, Galea S: Patterns of gun deaths across US counties 1999-2013. Ann Epidem 27:302-307, 307.e1-307.e3, 2017

3. Morrow KD, Podet AG, Spinelli CP, Lasseigne LM, Crutcher CL II, Wilson JD, et al: A case series of penetrating spinal trauma: comparisons to blunt trauma, surgical indications, and outcomes. Neurosurg Focus 46(3):E4, 2019

4. Naghavi M, Marczak LB, Kutz M, Shackelford KA, Arora M, Miller-Petrie M, et al: Global mortality from firearms, 1990-2016. JAMA 320:792-814, 2018

5. Ridell CA, Harper S, Cerdá M, Kaufman JS: Comparison of rates of firearm and non-firearm homicide and suicide in black and white non-Hispanic men, by US state. Ann Intern Med 168:712-720, 2018

6. Rowhani-Rahbar A, Zatzick D, Wang J, Mills BM, Simonetti JA, Fan MD, et al: Firearm-related hospitalization and risk for subsequent violent injury, death, or crime perpetration: a cohort study. Ann Intern Med 162:492-500, 2015

\section{Disclosures}

The author reports no conflict of interest.

\section{Correspondence}

R. John Hurlbert: rjhurlbert@surgery.arizona.edu.

INCLUDE WHEN CITING

DOI: 10.3171/2019.1.FOCUS1913. 